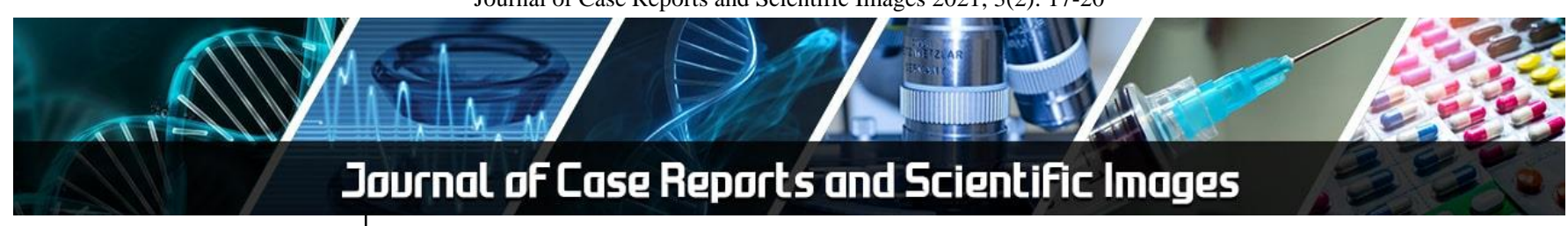

E-ISSN: 2708-0064

P-ISSN: 2708-0056

IJCRS 2021; 3(2): 17-20

www.allcasereports.com

Received: 16-06-2021

Accepted: 18-07-2021

Dr. Sathish Babu

Professor, Department of

Radiology, Sree Mookambika

Institute of Medical Sciences,

Kulasekharam, Tamil Nadu,

India

Dr. Jagadeep MR

Assistant Professor,

Department of Radiology,

Sree Mookambika Institute of

Medical Sciences,

Kulasekharam, Tamil Nadu, India

\section{Dr. Arif Khan S}

Assistant Professor,

Department of Radiology,

Sree Mookambika Institute of

Medical Sciences,

Kulasekharam, Tamil Nadu,

India

Dr. Vivek Kumar AS

Radiology Resident,

Department of Radiology,

Sree Mookambika Institute of

Medical Sciences,

Kulasekharam, Tamil Nadu,

India

\section{Dr. Suji M}

Radiology Resident,

Department of Radiology,

Sree Mookambika Institute of

Medical Sciences,

Kulasekharam, Tamil Nadu, India

\section{Dr. Vinod S}

Associate Professor, Department of Radiology, Sree Mookambika Institute of Medical Sciences,

Kulasekharam, Tamil Nadu, India

\footnotetext{
Corresponding Author: Dr. Vinod S

Associate Professor,

Department of Radiology,

Sree Mookambika Institute of

Medical Sciences,

Kulasekharam, Tamil Nadu,

India
}

\section{Role of MRI in the evaluation of painfull knee joint in a tertiary health care}

\author{
Dr. Sathish Babu, Dr. Jagadeep MR, Dr. Arif Khan S, Dr. Vivek Kumar \\ AS, Dr. Suji M and Dr. Vinod S
}

DOI: https://doi.org/10.22271/27080056.2021.v3.i2a.33

\begin{abstract}
Introduction: Knee joint injuries and disease conditions that cause disruption of ligament, menisci, articular cartilage and other structures causing painful knee result in significant morbidity and disability.

Aim: To describe the MRI features of various types of traumatic and non-traumatic lesions associated with painful knee.

Materials and Methods: This hospital based descriptive study was conducted in a tertiary care institute $(n=50)$ using 1.5T MRI for patients being referred to Department of Radiodiagnosis for the evaluation of painful knee were included in the study and results analysed by a descriptive analysis.

Results: Meniscal tears were the commonest soft tissue abnormality in our study. Posterior horn of the medial meniscus were commonly involved and mostly of Grade 3. Commonest type of meniscal tear was vertical tear and usually associated with history of trauma. The commonest manifestation affecting the ACL was tear, predominantly acute in nature. Complete PCL tear was the commonest manifestation among PCL abnormalities. One quarter of the patients had associated bone contusion, femur was predominantly involved followed by lateral tibial condyle. Acute ACL tears were particularly associated with bone contusions. Popliteal cyst was the commonest cystic lesion and usually associated with coexisting effusions and meniscal tears. Osteoarthritic process was most commonly involved in the Patello-femoral compartment.

Conclusion: For evaluation of painful knee, MRI is an accurate, cost-effective and a non-invasive choice of investigation. MRI can demonstrate the exact nature and extent of bony as well as soft tissue abnormality and is helpful in clinical decision making. Multiplanar imaging capacity of MRI enables a satisfactory diagnosis in such patients in whom a complete clinical examination is almost impossible due to pain.
\end{abstract}

Keywords: role, MRI, painfull knee joint, tertiary health care

\section{Introduction}

Knee pain accounts for more than one million emergency department and 1.9 million primary care outpatient visits annually and it is one of the largest and most complex joints in the body ${ }^{[1,2]}$. The disease processes and injuries that disrupt ligaments, menisci, articular cartilage and other structures of the knee cause painful knee resulting in significant morbidity and disability. Clinical examination is not usually conclusive to point out the exact location of the lesion causing pain. Hence optimum treatment is hampered. Because of that, non-invasive imaging modality which demonstrates the underlying pathology without much discomfort to the patient is needed. The imaging modalities which we are currently used to evaluate knee abnormalities including standard radiography, scintigraphy, Computed Tomography (CT), planar tomography and arthrography ${ }^{[1,2]}$. MRI has revolutionized the knee imaging in the present era. Substantial evidence exists in the literature comparing MRI with arthroscopic findings which has helped in validating the role of MRI for the evaluation of meniscal and ligamentous injuries ${ }^{[3]}$. Multiplanar imaging capability and superior soft tissue detail provides a distant advantage for MRI over other imaging modalities in addition to its non-invasive, non-operator dependent, and cost-effective nature ${ }^{[1,2]}$. Our study is aimed to identify common lesions in the knee joint and to describe the MRI features of various types of traumatic and non-traumatic lesions causing painful knee joint.

\section{Materials and Methods}

The present study was a hospital based observational study conducted in a Tertiary care centre in Tamil Nadu, India. The study included 50 patients with painful knee joint over a period extending from September 2020 to June 2021. 
Patients being referred for the evaluation of painful knee to the department of Radiodiagnosis were included in the study. Patients who could not co-cooperate for MRI examination, post-operative cases, neoplastic conditions and who had metallic implants or metallic clips in situ were excluded from the study. All the MRI scans of the knee in the present study were performed using Siemens 1.5 Tesla Magnetom Essenza MRI scanner. After MRI evaluation the various pathologies of the knee joint involving different compartments were tabulated and descriptive analysis is made in the form of percentages to explain the results. The MRI protocol consisted of the following sequences: T1 and T2 weighted sequences in sagittal planes, PD weighted sequences in axial, coronal and sagittal planes and fat suppressed T2 or STIR sequences wherever indicated. The ethical clearance from the Institute was obtained before starting the study and written informed consents were taken before enrolling the patients.

\section{Results}

In this study group of 50 patients, the age at presentation with knee pain ranged from 15 to 64 years. The mean age was 33.1 years and the maximum number of patients affected belonged to the 21-40 years age group. Out of 50 patients, $37(74 \%)$ were males and $13(26 \%)$ were females. Only 2 patients (4\%) were with normal MRI findings and 58 patients $(96 \%)$ were with abnormal MRI findings.

Table 1: Distribution of patients according to knee pathology

\begin{tabular}{|c|c|c|}
\hline pathology & No. of patients & percentage \\
\hline ACL & 30 & 60 \\
\hline PCL & 6 & 12 \\
\hline Lateral Mencius & 19 & 38 \\
\hline Medial Meniscus & 31 & 62 \\
\hline MCL & 17 & 34 \\
\hline LCL & 14 & 28 \\
\hline Bone & 25 & 50 \\
\hline Muscular & 1 & 2 \\
\hline Joint effusion & 41 & 82 \\
\hline
\end{tabular}

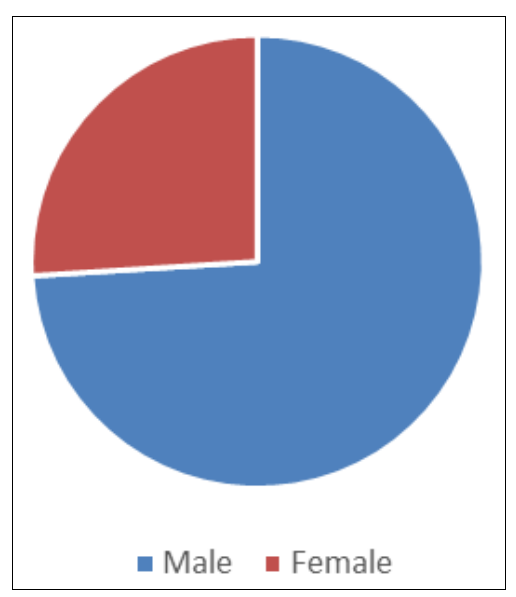

Fig 1: Distribution of patients according to sex

Meniscal Tear: Of the 50 patients evaluated with MRI of the knee for evaluating painful knee joint, 39 patients $(78 \%)$ had 50 meniscal tears. Of the 39 patients, $31(79.4 \%)$ involved the medial meniscus tear alone, $19(48.7 \%)$ had the lateral meniscus tear alone and $11(28.2 \%)$ had the medial as well as lateral meniscus tears. Of the 50 meniscal tears detected on evaluation with MRI of the knee, 38 tears $(76 \%)$ involved the posterior horn, 11 tears $(22 \%)$ involved the anterior horn while $8(16 \%)$ involved the body of the meniscus and $1(2 \%)$ involved the root of meniscus. Of the 31 medial meniscal tears, $5(16.1 \%)$ was Grade I tear, 9 (29\%) were Grade II tears, 13 (41.9\%) were Grade III tears and $4(12.9 \%)$ were Grade IV tears. Out of 31 medial meniscal tears, 26 tears $(83.8 \%)$ involved the posterior horn, 7 tears $(22.5 \%)$ involved the body of the meniscus, 3 tears $(9.6 \%)$ involved the anterior horn and 1 (3.2\%) tear involved the root of meniscus. Of the 19 lateral meniscal tears, $1(5.2 \%)$ were Grade I tears, $6(31.5 \%)$ were Grade II, $9(47.3 \%)$ were Grade III and $3(15.7 \%)$ were Grade IV tears. Out of 19 lateral meniscal tears, $12(63.1 \%)$ tears involved the posterior horn, $8(42.1 \%)$ tears involved the anterior horn and $1(5.2 \%)$ tear involved the body of the meniscus.

Table 2: Distribution of meniscal tears into various types

\begin{tabular}{|c|c|c|}
\hline Types of Meniscal Tears & No. of Tears & percentage \\
\hline Vertical Tear & 19 & 39.5 \\
\hline Horizontal Tear & 9 & 18.7 \\
\hline Complex Tear & 7 & 14.5 \\
\hline Bucket Handle & 5 & 10.4 \\
\hline Radial & 7 & 14.5 \\
\hline Root & 1 & 2 \\
\hline Total & 48 & 100 \\
\hline
\end{tabular}

ACL Lesions: Out of 50 patients, 30 patients (60\%) had ACL pathologies. 29 patients $(96 \%)$ had ACL tears and 1 patient $(4 \%)$ had myxoid degeneration. Out of 29 patients having ACL tear, 10 patients $(34 \%)$ had acute partial tear, 16 patients $(59 \%)$ had acute complete tear, 2 patients $(7 \%)$ had chronic tears of ACL.

PCL Lesions: In our study of 50 patients, 6 patients (12\%) had PCL pathologies. 5 patients $(80 \%)$ were found to have PCL tear and 1 patient $(20 \%)$ had myxoid degeneration. Out of 5 patients having PCL tear, $2(40 \%)$ of them had partial tear and $3(60 \%)$ had complete PCL tear.

Collateral ligament injuries: Of the 31 patients with ligament tears, 17 patients $(55 \%)$ had medial collateral ligament (MCL) tears. Of these 17 patients, 11 patients $(65 \%)$ had Grade I tear (sprain), 6 patients $(35 \%)$ had Grade II tear (Partial tear) and none of the patient had Grade III tear. Out of 31 patients showing ligament tears, 14 (45\%) patients were found to have LCL tears, Of these 14 patients, 6 patients $(43 \%)$ had Grade I tear (sprain), 4 patients (28.5\%) had Grade II tear (Partial tear) and 4 patients (28.5\%) had Grade III tear (Complete tear)

Bone Contusions: Bone contusions were more common in femur (18) than tibia (16). Contusions in the lateral femoral condyle (12) being more common than in the medial femoral condyle (4).

Table 3: Distribution of bone contusions in the bones forming knee

\begin{tabular}{|c|c|c|}
\hline Bone Contusion & Number of Contusions & percentage \\
\hline Tibia & 16 & 34 \\
\hline Femur & 18 & 38 \\
\hline Patella & 10 & 21 \\
\hline Fibula & 3 & 7 \\
\hline Total & 47 & 100 \\
\hline
\end{tabular}


Bone Fractures: A total of 7 bone fractures were seen in 6 patients out of which $4(57.1 \%)$ fractures involved the tibia, $2(28.3 \%)$ fracture involved the femur, and 1 (14.3\%) fracture involved the fibula.

Cystic lesions: In the current study 6 patients had a total of 6 cysts $(12 \%)$. Baker cyst was seen in $3(50 \%)$ patients, ganglion cyst was seen in $2(33 \%)$ patients and parameniscal cyst was seen in $1(17 \%)$ patient involving the medial meniscus and was associated with horizontal tear of the medial meniscus.

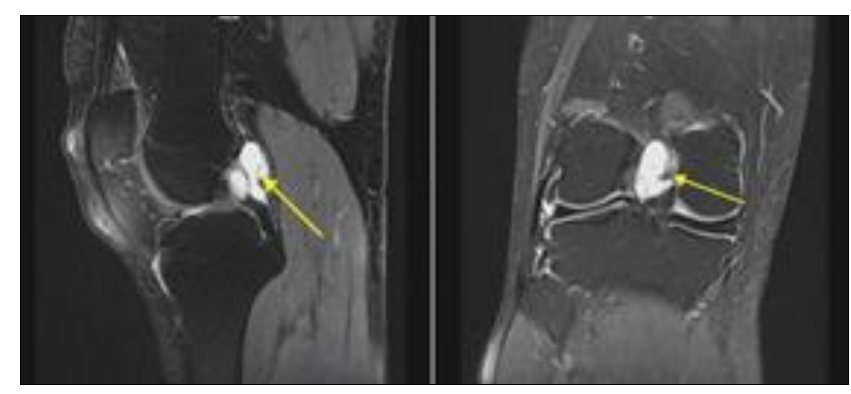

Fig 2: PDFS SAGGITAL (left side) and PDFS Coronal Image (right side) showing Ganglion Cyst

PD: Proton Density; FS: Fat Saturated

Osteoarthritis: MRI changes suggestive of osteoarthritis were found in $5(10 \%)$ patients, out of which $4(80 \%)$ had involvement of medial compartment, $1(20 \%)$ of the lateral compartment, $1(20 \%)$ patient had involvement of bilateral compartments and in $5(100 \%)$ patients, patellofemoral compartment was involved.

Synovial pathologies: In this study of 50 patients, Synovial pathologies were seen in $5(10 \%)$ patients. Out of 5 patients, $5(100 \%)$ patients had synovial hypertrophy.

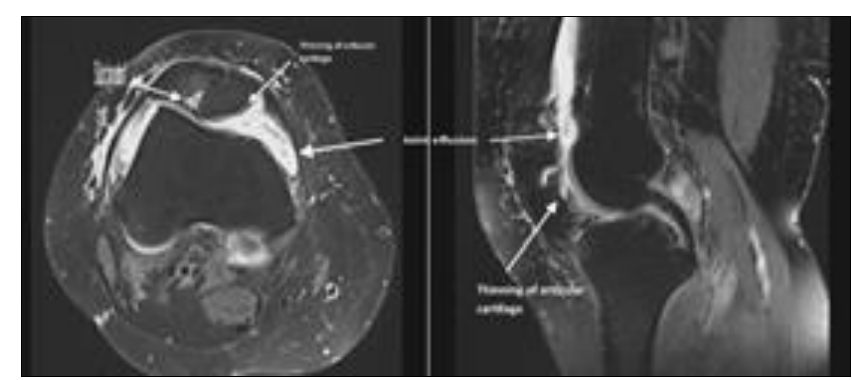

Fig 2: PD FS Axial Image (left side) and PD FS SAGGITAL Image (right) showing patello-femoral arthritis

\section{Discussion}

Present study was based on observational analysis by MRI for various causes of a painful knee joint. In the current study, we found that the mean age of the group was 33.1 years with a male dominance. The results are in concordance with Yadav R et al. study, with a mean age of $36.70 \pm 14$ years and a male preponderance ${ }^{[4]}$. Gimhavanekar S et al., Mansour MAM et al., and Singh JP et al. ${ }^{[5-7]}$ also showed male preponderance. The commonest soft tissue abnormality found in our study was meniscal tears, most commonly involving the posterior horns. The results are in concordance with the previously reported literature ${ }^{[7,9-12]}$. Grade-III tear was the commonest meniscal tear in the current study which is in concordance with the results by Arumugam et al., ${ }^{[13]}$. The commonest type of meniscal tear were found to be vertical tears which is in contrast with the previous finding of horizontal tear being the commonest meniscal type by Pasupuleti B et al., ${ }^{[9]}$. In our study the commonest tear associated with trauma were vertical tears. Reported literature also describes vertical tears as being traumatic in nature ${ }^{[9,10]}$. Three of our patient had bucket-handle tear in medial meniscus and two involving the lateral meniscus. Literature also reports that most of the bucket-handle tears involves the medial meniscus $[5,14]$. Acute Tear was the commonest lesion affecting the ACL. The results are comparable to the study done by Sohali $\mathrm{K}$ et al., ${ }^{[15]}$. The incidence of PCL pathology in our study was comparable to the $5.78 \%$ incidence reported by Singh JP et al., ${ }^{[7]}$. PCL pathology in our study was in accordance with the reported literature which showed partial PCL tear as the commonest pathology [9]. Quarter of our patients had bone contusion which compares well with the existing literature (28.3\%) ${ }^{[15]}$. Femur was more commonly involved than tibia by contusions and involvement of lateral femoral condyle was more frequent than its medial counterpart. Our results are in concordance with the existing literature ${ }^{[16]}$. Acute ACL tears were usually seen along with bone contusions in our study. Previous studies [13, 17, 18] also reported similar associations. Bakers cyst being the commonest cystic lesion (12\%) involving the knee joint in our study which is a similar finding reported previously by Sohali K et al., (10\%) [15]. The common association with Popliteal cysts were joint effusion, medial meniscal tear and ACL tear. MRI detects an associated disorder in $94 \%$ cases of popliteal cysts. Popliteal cyst associated with joint effusion, meniscal tear and ACL tear has been previously reported ${ }^{[19,20]}$. Meniscal cyst involving the posterior horn of medial meniscus and its association with horizontal tear is comparable with the literature reported ${ }^{[21]}$. Osteoarthritic process of the knee joint was most commonly involved in the Patello-femoral compartment, which is in accordance with the existing literature ${ }^{[22]}$. MR has been established as a choice of an effective non-invasive modality for identifying the knee pathologies ${ }^{[23,24]}$. The aim of the study is to emphasis the value of MR imaging in the evaluation of a painful knee and to evaluate its superiority over the conventional imaging (Xrays) and $\mathrm{CT}$ scan thereby resulting in a better clinical management.

\section{Limitation}

Small sample size and inability to correlate MR findings with the arthroscopic findings are the limitations of this particular study.

\section{Conclusion}

For depicting the anatomy of the knee joint MR imaging is an accurate, non-invasive technique and a cost effective modality which doesn't even need an intravenous contrast. Our study also demonstrates a significant role of MR imaging in the examination of a wide spectrum of knee abnormalities. MR imaging of the knee may helpful in decision making of the treatment protocol involving both surgical and medical management and is especially useful in the setting of indeterminate clinical findings. The accuracy of evaluation of meniscal tears as well as ACL lesions is high using MRI. 


\section{References}

1. Prickett WD, Ward SI, Matava MJ. Magnetic resonance imaging of the knee. Sports Med 2001;31(14):9971019.

2. Kean DM, Worthington BS, Preston BJ, Roebuck EJ, McKim-Thomas $\mathrm{H}$, Hawkes RC et al. Nuclear magnetic resonance imaging of the knee: examples of normal anatomy and pathology. The British journal of radiology 1983;56 (666):355-64.

3. Hartzman S, Reicher MA, Basset LW, Duckwiler GR. MR imaging of the knee Part II. Chronic disorders. Radiology 1987;162:553-57.

4. Yadav R, Kachewar SG. Role of MRI in evaluation of painful knee. IJMRHS 2014;3(1):84-87.

5. Gimhavanekar S, Suryavanshi K, Kaginalkar J, RoteKaginalkar.

6. V. Magnetic Resonance Imaging of Knee Joint: Diagnosis and Pitfalls Using Arthroscopy as Gold Standard. Int J Sci Stud 2016;4(1):110-16.

7. Mansour MAM, Ahmed RM, Alaaibrahim, Elhussein $\mathrm{N}$, Aljuaid SA. Magnetic resonance imaging diagnostic procedures for knee joint injuries. IOSR-Journal of Nursing and Health Sciences 2015;4(2):37-46.

8. Singh JP, Garg L, Shrimali R, Setia V, Gupta V. MR Imaging of knee with arthroscopic correlation in twisting injuries. Indian journal of radiology and imaging 2004;14(1):33-40.

9. Hetta W, Niazi G. MRI in assessment of sports related knee injuries. The Egyptian Society of Radiology and Nuclear Medicine 2014;45(4):1153-61.

10. Pasupuleti B, Kosti SK, Narra R, Jukuri N. MRI evaluation of painful knee. J of Evidence Based Med and Health Care 2015;2(7):888-97.

11. Kelly EA. Berquist MRI of the musculoskeletal system: Knee (5th edn.) Lippincott, Williams and Wilkins 2006, 307-21.

12. Crues JV, Richard R, Morgan FW. Meniscal pathology: The expanding role of magnetic resonance imaging. Clinical Orthopaedics and Related Research. 1990;252:80-86.

13. Pame M, Gayan M, Hazarika K, Roy DKR. MRI evaluation of painful knee joint- the correlation of multiple coexisting pathologies, age and sex. J Evid Based Med Health 2017;4(18):1019-27.

14. Arumugam V, Ganesan GR, Natarajan P. MRI Evaluation of Acute Internal Derangement of Knee. Open Journal of Radiology 2015;5:66-71.

15. Wright DH, De Smet AA, Norris M. Bucket-handle tears of the medial and lateral menisci of the knee: value of MR imaging in detecting displaced fragments. AJR American Journal of Roentgenology 1995;165(3):621-25.

16. Sohail K, Ayesha H, Shireen K, Zahir S, Ambreen S, Rehana B. Role of MRI in painful knee. Ann Pak Inst Med Sci 2015;11(3):137-41. Mathis CE, Noonan K, Kayes K. "Bone bruises" of the knee: a review. The Iowa Orthopaedic Journal 1998;18:112-17.

17. Wright DH, De Smet AA, Norris M. Bucket-handle tears of the medial and lateral menisci of the knee: value of MR imaging in detecting displaced fragments. AJR American Journal of Roentgenology 1995;165(3):621-25.

18. Sohail K, Ayesha H, Shireen K, Zahir S, Ambreen S, Rehana B. Role of MRI in painful knee. Ann Pak Inst
Med Sci 2015;11(3):137-41.

19. Mathis CE, Noonan K, Kayes K. "Bone bruises" of the knee: a review. The Iowa Orthopaedic Journal 1998;18:112-17.

20. Miller TT, Staron RB, Koenigsberg T, Levin TL, Feldman F. MR imaging of Baker cysts: association with internal derangement, effusion, and degenerative arthropathy. Radiology 1996;201(1):247-50.

21. Sansone V, De Ponti A, Paluello GM, del Maschio A. Popliteal cysts and associated disorders of the knee: critical review with MR imaging. Int Orthop 1995;19(5):275-79.

22. Campbell SE, Sanders TG, Morrison WB. MR imaging of meniscal cysts: incidence, location, and clinical significance. American Journal of Roentgenology 2001;177(2):409-13.

23. Peterfy CG, Guermazi A, Zaim S, Tirman PF, Miaux Y, White $\mathrm{D}$ et al. Whole-organ magnetic resonance imaging score (WORMS) of the knee in osteoarthritis. Osteoarthritis and Cartilage 2004;12(3):177-90.

24. Pompan DC. Reassessing the role of MRI in the evaluation of knee pain. Am Fam Physician 2012;85:221-24.

25. Shah D, Naware S, Bhatnagar S, Kulkarni VM. Role of magnetic resonance imaging in the evaluation of articular cartilage in painful knee joint. Med J DY Patil Univ 2014;7:160-65. 